\title{
Investigation of Injection Shrinkage of Composite Moldings with Mineral Filler
}

\author{
Tomasz Jachowicz ${ }^{1, *}$, Volodymyr Krasinskyi ${ }^{2}$ \\ ${ }^{1}$ Lublin University of Technology, Faculty of Mechanical Engineering, Department of Polymer Processing; Poland, 20-618 Lublin, Nadbystrzycka 36 \\ ${ }^{2}$ Lviv Polytechnic National University, Department of Chemical Technology of Plastics, Ukraine, 79013 Lviv, 12 S. Bandera str.
}

\begin{abstract}
The paper presents the injection shrinkage of composite moldings with mineral filler phenomenon. The definition of shrinkage and shrinkage types are described. The main factors affecting shrinkage value of injection-molded part are discussed. Based on the experimental tests conducted using injection-molded parts made from polypropylene filled with glass fiber and talc, the dependence of injection-molded part shrinkage on filler content and selected parameters of the injection molding process has been determined.
\end{abstract}

Keywords: polymer processing; injection molding; shrinkage; filler; composite injection-molded part.

\section{Introduction}

The injection molding is one of the most important manufacturing process for producing parts made of polymer materials. There are many different variants of this process, all of them characterized by cyclical nature. Injection molding can be used to process practically all kinds of polymer materials, particularly thermoplastic and thermoset materials, but also rubber compounds, liquid silicones and composite materials. As a result of injection molding, an injection-molded part is produced; depending on both the injection molding process variant employed and the polymer used, the injection-molded part is characterized by a very wide range of functional and strength properties as well as variations in shape, structure, dimensions and production accuracy $[2,4,9,15,19]$.

Injection-molded part design is predominantly affected by the following: polymer type, processing method and molding conditions, tool design and injection molding machine processing capacity. All these factors directly or indirectly affect the final dimensions, structure and shape of the injection-molded part, its consistency with the tolerance range adopted during the design process and molding anomalies (material and surface defects) that are significant from a user's point of view [7, 12, $18]$.

\section{Factors Affecting Shrinkage}

With its origin in physiochemical phenomena, shrinkage is affected by many factors that can be grouped according to the following: $[1,4,9,12,20]$ :

$\checkmark$ polymer material (density, molecular weight, crystalline or amorphous structure),

$\checkmark$ part (shape, dimensions, dimensional accuracy and tolerance range),

$\checkmark$ processing conditions (polymer temperature, mold temperature, product cooling and cooling method applied),

$\checkmark$ tool design (flow system design, mold cavity shape),

$\checkmark$ physical or chemical treatments applied to the molded part (normalizing, annealing, chlorination). 
The effect of processing conditions on molding shrinkage is difficult to determine. When thermoplastics are processed by the injection molding technique, shrinkage is mainly caused by the decreasing temperature of the polymer being processed in the final stages of the injection cycle, and it depends on the technological parameters of this process (temperature, pressure, time and cooling conditions) as well as on the parameters of subsequently employed thermal and thermochemical treatments. In contrast, when thermoset plastics are processed by the compression method, compression shrinkage is significantly affected by chemical processes that occur in the polymer being processed at the final stages of the compression cycle $[4,5,12]$.

It has been established that crystalline materials are more prone to shrinkage than amorphous materials $[1,8,11]$. The shrinkage phenomenon has been best investigated for the injection molding process, hence the majority of dependences describing the effect of molding conditions on shrinkage value have been formulated with regard to injection-molded parts. Table 1 lists values of linear primary shrinkage for the most important polymer materials [16].

Table 1: Value of linear primary shrinkage [16].

\begin{tabular}{|l|l|}
\hline Polymer type & Shrinkage value [\%] \\
\hline Polystyrene & $0.5-0.7$ \\
\hline ABS resins & $0.4-0.6$ \\
\hline Low-density polyethylene & $1.0-1.5$ \\
\hline $\begin{array}{l}\text { High-density polyethy- } \\
\text { lene }\end{array}$ & $2.0-4.0$ \\
\hline Polyamide & $1.2-3.0$ \\
\hline Poly(vinyl chloride) & $0.1-0.4$ hard \\
\cline { 2 - 2 } & $1.0-3.5$ soft \\
\hline Polypropylene & $1.0-2.0$ \\
\hline Poly(methyl methacrylate) & $0.4-0.8$ \\
\hline Polycarbonates & $0.4-0.8$ \\
\hline Polyoxymethylene & $3.0-5.0$ \\
\hline
\end{tabular}

Polymer materials with higher density exhibit higher shrinkage. It is particularly important in the case of polyolefines, polyamides and polyacetals. Polymers with lower density crystallize to a lower degree due to their stronger chain branching, which leads to lower shrinkage. Shrinkage decreases with the increase in melt flow rate $[1,4$, 14].

Injection molding parameters, in particular pressure and holding time as well as mold temperature and cooling time, have a significant effect on shrinkage $[1,4,11,13]$. Generally, if the injection pressure, holding pressure and holding time are increased, injection shrinkage of thermoplastics decreases, whereas increasing the mold temperature, melt temperature and injection rate leads to increased shrinkage. If the holding time is too short, which is usually the outcome of premature freeze-off, or if the holding pressure is too low, depressions or shrinkage cavities can occur. If the holding pressure is too high, it results in excessive increase in polymer pressure and its packing in the mold cavity, leading to scratches and cracking of the injection-molded part [1, 4, 5, 11]. The temperature of the mold cavity surface and the wall thickness of the molded part determine the cooling rate uniformity. With extending the cooling time and increasing the wall thickness of the molded part, the heat transfer becomes slower, so, as a consequence, the molecule chains have more time to level up the stresses, while semicrystalline materials have more time even for crystallization $[3,4,10]$. Although the increase in the mold temperature leads to the increase in overall shrinkage, the fraction of primary shrinkage is then so low that sufficient dimensional accuracy of the molded part can still be obtained $[3,5,7,19]$.

The injection-molded part design and the way of polymer feed determine shrinkage uniformity in particular fragments of the molded part. The non-uniformity of wall thickness leads to different shrinkage values, which induces internal stresses and warpage $[4,11,17,20]$. With very thin walls of molded parts, strong macromolecule orientation and anisotropic shrinkage occur. Shrinkage is clearly lower if the molded part does not have any sharp edges, for example in the place where a bottom changes into a side wall. This is due to the fact that rounded shapes facilitate polymer flow, which results in lower pressure losses [7, 9, 12].

The design of the injection mold is critical to shrinkage uniformity in the injection-molded part. The most commonly mentioned design factors that affect shrinkage value are as follows: the number and arrangement of mold cavities, 
flow path length, type of a gating system as well as the place where the polymer is forced into the mold cavity, cross section and shape of pinpoint gates as well as the arrangement of temperature adjusting channels. Parts molded in multi-cavity molds are characterized by considerable variations in shrinkage values. Shrinkage increases along the polymer flow direction in the mold injection channels with the increase in the distance of the mold cavity from the central injection channel. This is due to the decrease in the pressure along the polymer flow path. Shrinkage is lower in the vicinity of the ingot than at the distant edge of the molded part; for this reason, many injection points are used to level out shrinkage value $[7,12,20]$.

Anisotropic shrinkage of polymer materials without fillers is relatively low, particularly in the case of amorphous materials. The anisotropy of filled materials mainly depends on the filler content and shape, the shape and dimensions of the molded part, the way of forcing polymer into the mold cavity (which is connected with mold cavity filling and filler orientation), as well as the dimensions and shape of the pinpoint gate $[3,7$, $13,14]$.

As additional substances, fillers are introduced into the material at different stages of processing, therefore they significantly change both the properties of products obtained and the process itself. As far as the injection molding process is concerned, fillers, both as powders and short fibres, exert a positive impact as they lead to the reduction in injection molding shrinkage and the dimensional stability of the injection-molded part. Depending on injection molding conditions and the structure of the injection-molded part, the application of fibrous fillers can result in distinct fiber orientation, which leads to anisotropic shrinkage. The addition of fillers can however deteriorate the operational conditions of the injection molding machine however deteriorate, exerting an erosive impact on the barrel and screw surfaces; what is more, some fillers impair the rheological properties of plastics and make polymer flow difficult $[4,7,13]$.

A detailed discussion of the effect of individual factors on the shrinkage phenomenon is beyond the scope of the present paper. However, the problem has been thoroughly presented in the literature $[4$, $8,9,11]$. To give an example of the effect of selected factors on shrinkage value, the dependence of injection shrinkage of polypropylene filled with talc as a function of talc content is shown in Fig. 1 [6]. To give an another example of the effect of selected factors on shrinkage value, the dependence of injection shrinkage of polypropylene filled with glass fiber as a function of glass fiber content is shown in Fig. 2 [6].

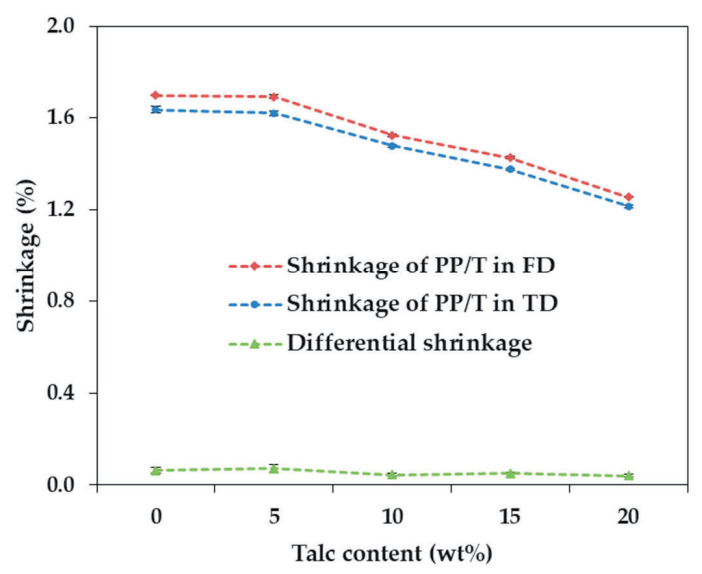

Fig. 1: Example of injection shrinkage of polypropylene filled with talc as a function of talc content [6].

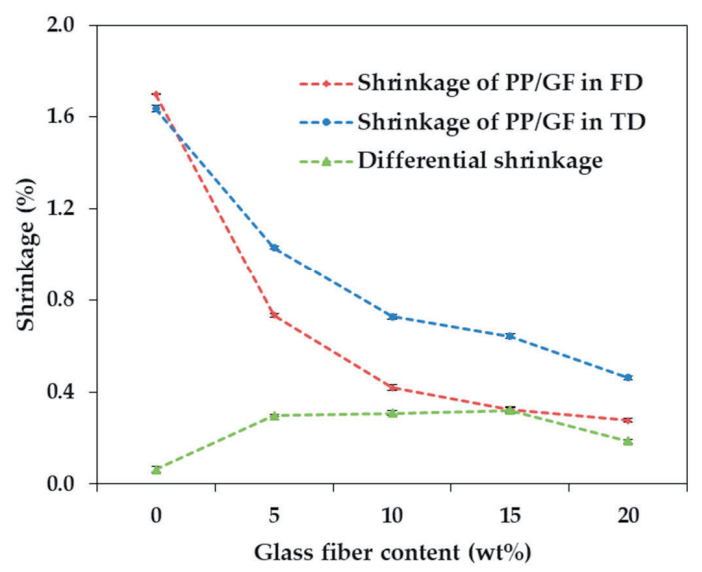

Fig. 2: Example of injection shrinkage of polypropylene filled with glass fibre as a function of glass fibre content [6].

\section{Experimental Procedure}

To conduct the experimental tests investigating the effect of filler type and content as well as of selected parameters of the injection molding process on linear shrinkage value, injection-molded parts in the shape of tensile test specimens were used. The injection-molded parts were obtained 
using a laboratory screw injection molding machine, with the variable factors being: injection time set to 4 and 6 seconds, cooling time set to 15, 30 and 45 seconds, respectively. The samples used to test the injection shrinkage were in the shape of samples for measuring tensile strength (in accordance with PNEN ISO 527-1:2012) and were made using an Arburg Allrounder 320 C Golden Edition injection molding machine. The injection-molded parts were made of polypropylene marketed under the name of Moplen EP440G, manufactured by Basell Orlen Polyolefins. The fillers used included: short glass fibre, as a ready PP/GF concentrate, and talc, also in the form of a ready $\mathrm{PP} / \mathrm{T}$ concentrate. For injection, polymer batches containing: $10 \%, 20 \%, 30 \%, 40 \%$ and $50 \%$ of glass fibre, $10 \%, 20 \%, 30 \%$ and $40 \%$ of talc, and raw propylene without filler, were used. The temperature in particular heating zones of the plasticizing system was increased from $220^{\circ} \mathrm{C}$ to $240^{\circ} \mathrm{C}$, reaching $245^{\circ} \mathrm{C}$ in the injection nozzle. The tool used was a twocavity injection mold thermostatic at a temperature of $50^{\circ} \mathrm{C}$. Necessary for further calculations of linear shrinkage, the dimensions of the mold cavity were as follows: length $L=152.00 \mathrm{~mm}$, width $\mathrm{H}=20.15 \mathrm{~mm}$ and thickness $B=4.00 \mathrm{~mm}$.
Corresponding to the dimensions of the mold cavity, the actual geometric dimensions of the injection-molded parts produced with particular batches, differing in filler type and content and obtained at different injection parameters, were measured with an accuracy of $0.01 \mathrm{~mm}$ by means of an electronic measuring device (digital caliper). The measurements were made three times: immediately after demolding (to analyse primary shrinkage), after twenty-four hours and after one week (to analyse secondary shrinkage). Following the preliminary calculations, the length $L$ of the injection-molded part, as the longest dimension of the examined product, was used for further presentation of the results.

\section{Results and Discussion}

Fig. 3 and Fig. 4 offer examples of the charts illustrating the change in the dimension $L$ of the injection-molded part after demolding as a function of the injection time and cooling time of this part. Extending the injection time and cooling time led to increasing the values of the investigated linear dimensions, whereas the differences between the corresponding dimensions were the clearer, the lower the filler content.

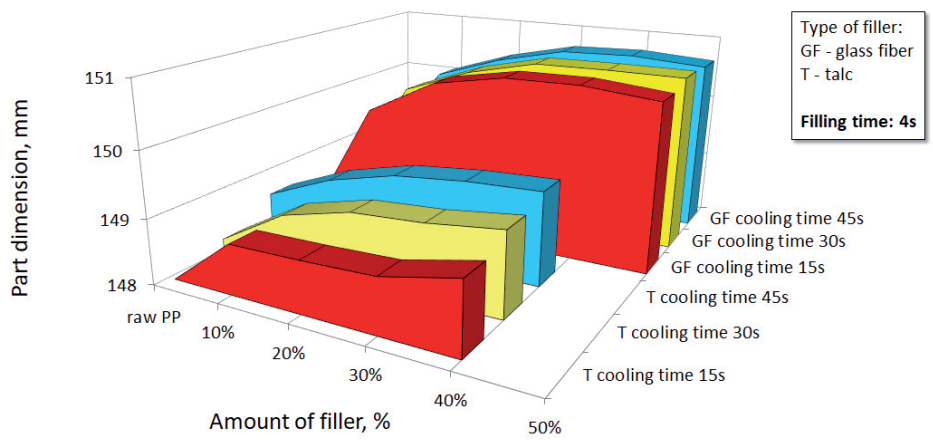

Fig. 3: Change in the dimension L of the glass fibre-filled part and talc filled part after demolding, depending on the filler content and cooling time of the part in the mold. The part was produced at filling phase time equal $4 \mathrm{~s}$.

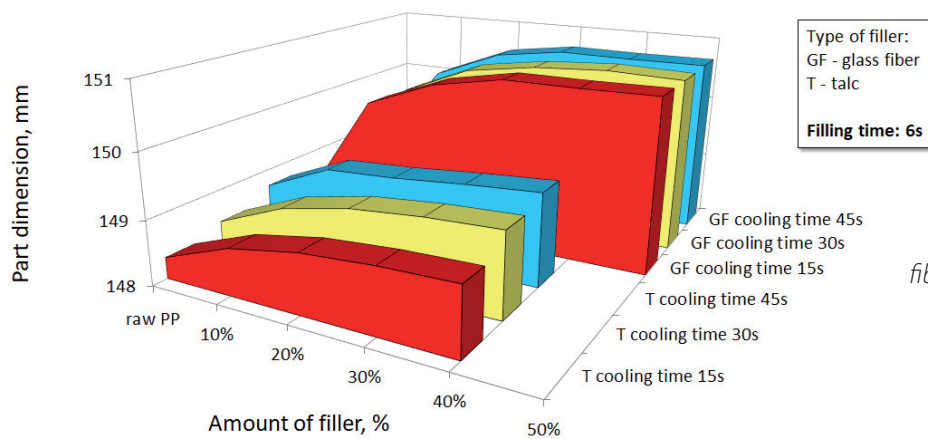

Fig. 4: Change in the dimension L of the glass fibre-filled part and talc filled part after demolding, depending on the filler content and cooling time of the part in the mold. The part was produced at filling phase time equal $6 \mathrm{~s}$ 


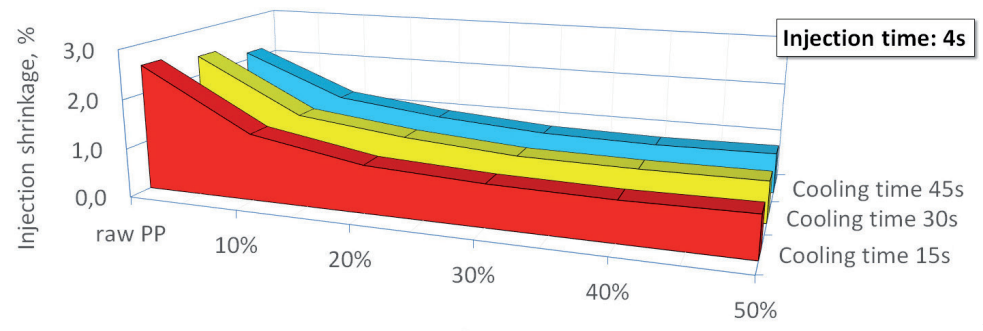

Amount of GF, \%

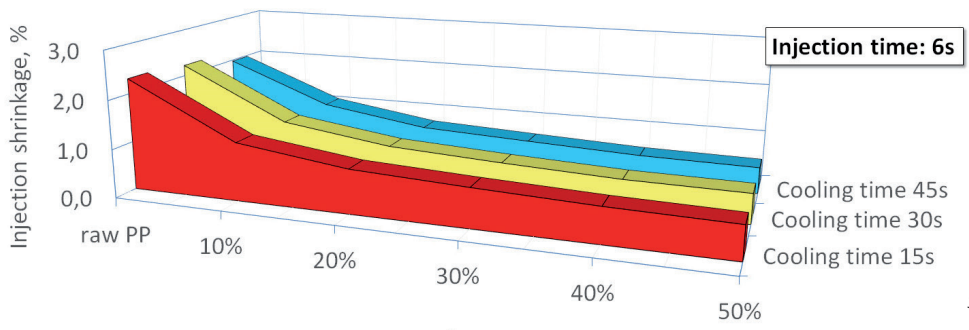

Amount of GF, \%

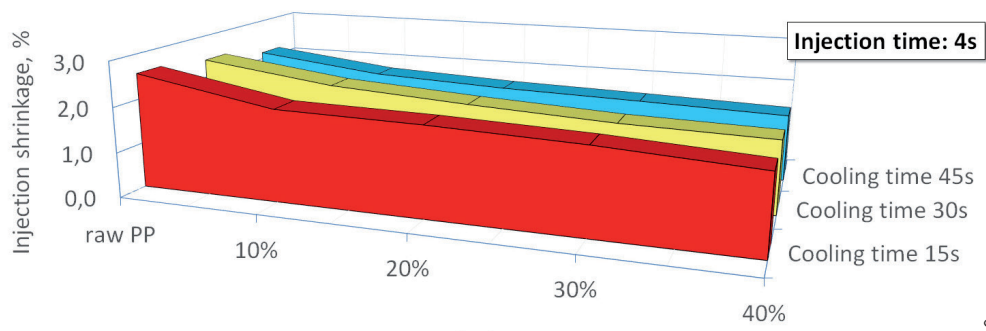

Amount of talc, \%

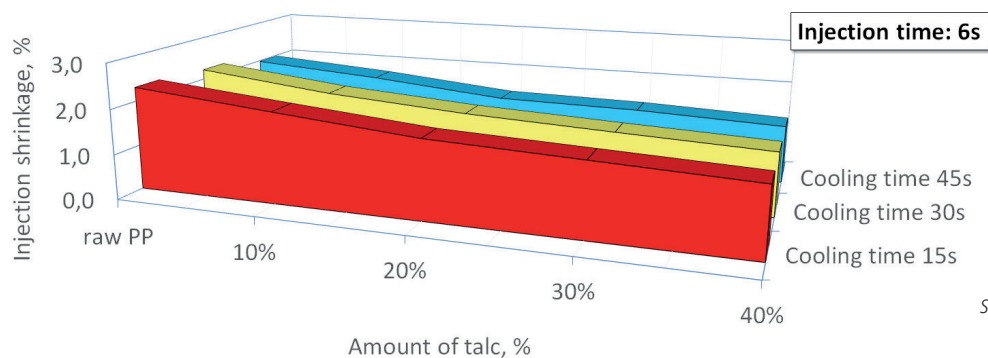

Fig. 5: Influence of the glass fibre content and cooling time on the linear injection shrinkage of polypropylene injection-molded parts produced at filling phase equal $4 \mathrm{~s}$.

Fig. 6: Influence of the glass fibre content and cooling time on the linear injection shrinkage of polypropylene injection-molded parts produced at filling phase equal $6 \mathrm{~s}$.

Fig. 7: Influence of the talc content and cooling time on the linear injection shrinkage of polypropylene injection-molded parts produced at filling phase equal $4 \mathrm{~s}$.

Fig. 8: Influence of the talc content and cooling time on the linear injection shrinkage of polypropylene injection-molded parts produced at filling phase equal $6 \mathrm{~s}$.
Fig. 5, Fig. 6, Fig. 7 and Fig. 8 present the effect of the injection time and cooling time on the values of linear injection shrinkage, depending on the filler type and content.

Increasing the filler content led to decreased shrinkage, this effect being most visible for the glass fibre-filled part whose shrinkage sometimes decreased nearly twice compared to the shrinkage of the part without any filler. The addition of talc resulted in decreased shrinkage, too, yet the decrease was not as considerable as in the case of glass fibre. With glass fibre, the decrease in shrinkage could be observed when the filler content was changed from $10 \%$ to $20 \%$ and, next, to $30 \%$. A further increase of the glass fibre content in polypropylene did not cause any visible decrease in shrinkage. As for the talc filler, the decrease in shrinkage was not as considerable as the one observed for glass fibre, and it proceeded at a uniform rate along with increasing the talc content in the material.

The extension of the injection time, which enables higher polymer packing in the mold cavity, affected the increase in the part dimensions more 
than the extension of the cooling time of the part in the mold.

\section{Conclusions}

Given both the complexity of the injection molding process for polymer materials and a relatively high number of factors that affect the process and its results, it is necessary that polymer properties, tool design and machine processing capacity be known in order to determine the optimal conditions of injection molding. The performed experimental tests were undertaken to investigate selected problems of the injection molding process, including factors such as changes of the polymer type being processed (filler type and content) and changes in some relatively easily adjustable injection parameters (injection time and cooling time of the part in the mold). The phenomenon of injection molding shrinkage of polymer materials, which changes both the shape and dimensions of the molded part, is one of the fundamental problems to be solved at the stage of both tool design and parameter selection for this processing method. The conducted analysis of injection molding shrinkage has demonstrated that shrinkage value can be effectively affected if injection molding conditions are selected properly, within the processing capacity of the injection molding machine; if necessary, it is also possible to modify the processing properties of polymers in order to produce molded parts with the desired geometric and strength properties. Both increasing the filler content in the polymer to a given value and extending the injection molding time (by increasing the injection time and cooling time) led to a clear decrease in injection molding shrinkage and, as a result, increased the dimensional accuracy of the injection-molded parts obtained, which means better production quality and enhanced applicability of such parts.

\section{References and Notes}

[1] Bociąga E., Jaruga T., Sikora R.:Wybrane zagadnienia wtryskiwania precyzyjnego. Cz. II. Czynniki wpływające na jakość wyprasek precyzyjnych. Polimery 2009, 54, 7-8, 522-529.

[2] Bociąga E.: Specjalne metody wtryskiwania tworzyw polimerowych. WNT, Warszawa 2008.

[3] Dulebova L., Greškovič F., Spišák E., Duleba B., Garbacz T.:The impact of the amount of filler on the properties of polymer materials. Kovárenství 2012, 44, 33-36.

[4] Fisher J. M.: Handbook of molded part shrinkage and warp- age. Plastic Design Library, William Andrew Inc., Norwich 2003.

[5] Gershon A. L, Gyger L. S., Bruck H. A., Gupta S. K.: Thermoplastic polymer shrinkage in emerging molding processes. Experimental Mechanics 2008, 48, 6, 789-798.

[6] Youngjae Ryu, Joo Seong Sohn, Byung Chul Kweon, Sung Woon Cha: Shrinkage Optimization in Talc- and Glass-FiberReinforced Polypropylene Composites. Materials 2019, 12, 764; doi:10.3390/ma12050764.

[7] Kazmer D. O.: Injection mold design engineering. Carl Hanser Verlag, Munich 2007.

[8] Kwon K., Isayev A. I., Kim K. H., van Sweden C.: Theoretical and experimental studies of anisotropic shrinkage in injection moldings of semicrystalline polymers. Polymer Engineering \& Science 2006, 46, 6, 712-728.

[9] Malloy R. A.: Plastic Part Design for Injection Molding. An Introduction. Carl Hanser Verlag, Munich 1994

[10] Polyplastics catalogue: Acetal Copolymer Duracon M90-44. Datasheet. Polyplastics Digital Library (www.polyplastics. com).

[11] Postawa P.: Skurcz przetwórczy wyprasek a warunki wtryskiwania. Polimery 2005, 50, 3, 201-207.

[12] Rosato D. V., Rosato D. V., Rosato M. G.: Injection Molding Handbook. Kluwer Academic Publisher, Norwell 2000.

[13] Shelesh-Nezhad K., Taghizadeh A.: Shrinkage behavior and mechanical performances of injection molded polypropylene/talc composites. Polymer Engineering \& Science 47, 12 , 2007, 2124-2128.

[14] Sikora J. W., Greškovič F.: Wpływ rodzaju napełniacza oraz czasu ochładzania na właściwości mechaniczne wyprasek wtryskowych z osnową polipropylenową. Przetwórstwo tworzyw 2010, 16, 5, 273-279.

[15] Sikora R., Jachowicz T.: Wpływ czasu ochładzania na skurcz przetwórczy wytworów otrzymanych metodą wytłaczania z rozdmuchiwaniem. Polimery 2000, 45, 10, 713-719.

[16] Sikora R.: Przetwórstwo tworzyw wielkocząsteczkowych. Wydawnictwo Edukacyjne. Warszawa 1993.

[17] Slota J., Spišák E., Gajdoš I.: Modern approaches in development of plastic products. Journal for Technology of Plasticity, 34, 1-2, 2009, 97-104.

[18] Smorawiński A.: Technologia wtrysku. WNT, Warszawa 1989.

[19] Yang S. S., Kwon T. H.: Numerical and experimental investigation of shrinkage behavior of precision injection molded articles. Polymer Engineering \& Science 2008, 48, 8, 1569 1583.

[20] Zawistowski H., Frenkler D.: Konstrukcja form wtryskowych do tworzyw termoplastycznych. Wydawnictwo Poradników i Książek Technicznych Plastech, Warszawa 2003. 